\title{
Sexualidad y exceso en el filme Ninfomaníaca del director Lars von Trier*
}

\author{
Sexuality and excess in the filme Nymphomaniac by the \\ director Lars von Trier
}

\author{
Sexualidade e excesso no filme Ninfomaníaca do \\ diretor Lars von Trier
}

\section{María Isabel Restrepo Mejía* \\ Sofía Fernández Fuente}

\section{Resumen}

En este artículo se presentan los resultados de la investigación "El exceso de la sexualidad en Joe, una mujer de la época actual, develado a través de su discurso en el filme Ninfomaníaca del director Lars von Trier". Cómo se presenta este exceso fue la pregunta que orientó la investigación, siendo el decir de Joe, mujer protagonista del filme, el que se analizó a partir de los conceptos psicoanalíticos que este fue convocando, para dar cuenta de los efectos de la no articulación de la sexualidad con la ley por parte de sus padres, ante el descubrimiento de la satisfacción sexual a través de su cuerpo a temprana edad, lo que precipitó en ella una elección de goce que se refuerza en su adolescencia por el desencuentro con el amor y el encuentro contingente con una propuesta que la lleva a un modo de goce y repetición. En la vida

\footnotetext{
* En el presente artículo se muestran los resultados de la investigación El exceso de la sexualidad en Joe, una mujer de la época actual, develado a través de su discurso en el filme Ninfomaníaca del director Lars von Trier, realizada en el año 2015 en la Institución Universitaria de Envigado.

** Psicóloga, Institución Universitaria de Envigado, mirm85@hotmail.com

*** MSc en Ciencias Sociales: Psicoanálisis, Cultura y Vínculo Social. Docente de la Institución Universitaria de Envigado y Universidad de Antioquia. Coordinadora de la línea de investigación de Estudios éticos, estéticos y comunicativos del Grupo de investigación PAYS de la IUE, Asociada a la NEL-Medellín, hoisis@yahoo.com
} 
adulta, esta elección degrada sus vínculos amorosos y termina por desencadenar lo que en el psicoanálisis se ha llamado el goce femenino.

Palabras clave: Otro, sexualidad, amor, goce, goce femenino.

\begin{abstract}
This article is made up of several moments that allow the development of the research proposal "Excess sexuality Joe, a woman of today, revealed through his speech at the nymphomaniac filme director Lars von Trier". How this excess was presented was the question that guided this research. The analysis of the Joe's narrative was made by means of the system of concepts of the psychoanalysis theory, to show the effects of non-articulation of sexuality with the law by their parents when Joe discovery of the sexual pleasure at an early age accelerate in her a choice of pleasure that is reinforced in the adolescence for a disagreement with love and the contingency in the excess that makes sexuality a pleasure and repetition manner. In her adult life, this choice takes her to a deterioration of her love bonds which ends up unchaining what psychoanalysis calls feminine jouissance.
\end{abstract}

Keywords: Other, sexuality, love, jouissance, feminine jouissance.

\title{
Resumo
}

Este artigo apresenta os resultados da pesquisa "O excesso da sexualidade na Joe, uma mulher moderna, revelado através de seu discurso no filmee Ninfomaníaca do diretor Lars von Trier”, Como se apresenta esse excesso foi a pergunta que orientou a pesquisa, sendo a fala da Joe, mulher protagonista do filmee, que foi analisada a partir de conceitos psicanalíticos que foram utilizados para dar conta dos efeitos da não-articulação da sexualidade com a lei por seus pais, antes da descoberta da satisfação sexual através de seu corpo em uma idade precoce, precipitando-lhe uma escolha do prazer que é reforçada na 
adolescência pela discordância com amor e encontro contingente com uma proposta que leva à um modo de gozo e repetição. Na vida adulta, esta escolha degrada os seus laços de amor e acaba provocando o que a psicanálise tem chamado de o gozo feminino.

Palavras-chave: Outro, sexualidade, amor, gozo, gozo feminino.

\section{Introducción}

El exceso en la sexualidad de una mujer, es el tema que suscita la realización de la investigación y posteriormente de este artículo, que se desarrolla a partir del discurso de Joe, el personaje principal del filme ninfomaníaca, presentado en el Festival de Cine de Berlín en diciembre de 2013, bajo la dirección de Lars von Trier, producción de Peter Aalbæk Jensen y la actriz Charlotte Gainsbourg como Joe, que por medio de ocho capítulos nos da a conocer, cómo el arte, en este caso, su variante del cine es una forma discursiva de narrar la realidad, e igualmente nos da a conocer como el discurso es una manera de expresarla y construirla, siendo el paradigma discursivo el medio a través del cual se reconoce al lenguaje en su función informativa e interpretativa, así como creativa o generativa de diferentes sentidos, incluyendo el existencial. Esta doble naturaleza del discurso según Santander (2011), no muestra de forma transparente un fenómeno, por lo tanto, requiere ser interpretado para develar lo que le dio forma y origen (pp.207-224).

En este artículo se describen los elementos subyacentes en las elecciones de Joe con respecto a su sexualidad, caracterizados por el exceso. Por lo tanto, se presentarán los hallazgos de la investigación consignados en tres capítulos que dan cuenta del análisis del discurso de la protagonista a lo largo del filme y cómo éste fue develando sus encuentros y desencuentros en el amor, y las vivencias de su sexualidad en la infancia, la latencia y la adolescencia y vida adulta. 


\section{Metodología}

La investigación se orientó por el método análisis del discurso, utilizado por las ciencias sociales para leer la realidad a través de los diferentes discursos que se encuentran en la sociedad, como los textos, las entrevistas, y los diálogos, los cuales se componen de signos de diferente índole. Análisis que se hace importante por no asumir los diversos signos por sí mismos, sino que la lectura de estos se hace según el periodista Pedro Santander (2011), en su artículo “¿Por qué y cómo hacer Análisis del discurso?”, teniendo en cuenta la opacidad del lenguaje, que significa que este no es transparente, algunas veces lo que se expresa comunica lo que se piensa, pero otras veces simplemente puede ser indicios, por esto es necesario hacer el uso de este método para llegar a una interpretación (pp.1-2).

Para llevar a cabo este análisis, fue necesario hacer uso de los materiales de expresión de un filme. Para ello se partió de la afirmación de Francesco Casseti \& Federico Di Chio (1991), que un filme expresa, significa y comunica por medio de diferentes formas de lenguaje que son nombrados como significantes, estos son los visuales y sonoros en los que se contienen otros cinco significantes que son: las imágenes, los signos escritos, voces, ruidos y música, que los autores los han llamado como cinco materiales de expresión (p.67).

Para esta investigación, se tomó como principal objeto de análisis el discurso de Joe, aunque hay elementos visuales y sonoros que hacen una composición con la historia y con la narrativa del personaje principal, no se hizo énfasis en éstos, ya que lo que interesa en este caso, es la historia contada por la protagonista del filme, la que se analizó desde el referente teórico del psicoanálisis. Lo que se presenta a continuación son los resultados de este análisis. 


\section{Resultados y su discusión \\ El encuentro con la satisfacción sexual sin el límite del otro materno y} paterno

\section{En la infancia: el encuentro con la satisfacción sexual}

El filme ninfomaníaca cuenta la historia de una mujer que se nombra como ninfómana, y en su relato hace un recorrido por las vivencias que tuvo en la infancia, la adolescencia y la edad adulta. Son estos tres momentos destacados en este trabajo, resaltando como aspectos fundamentales los encuentros y desencuentros que hubo en cada uno de éstos, y que fueron marcando el devenir de los excesos en su satisfacción sexual.

"Como nadie me orientaba a qué hacer, decidí ordenar todo a mi manera para
alivianar las aguas", frase que aparece cuando Joe narra un episodio en su pri-
mer lugar de trabajo, pero que pareciese ser el rasgo más propio de su infancia.
Esto se puede pensar a partir de la relación que tuvo con sus padres y de su
saber acerca de la sexualidad, particularidades que suscitaron en ella la elección
de goce. El término goce es definido por Lacan (1972) como lo que no tiene al-
guna utilidad y que constituye un aspecto negativo para el sujeto (p.3), aspecto
que se irá desarrollando a partir de la narrativa de la protagonista.

Las primeras escenas de la película, develan como la infancia, es el comienzo de lo que sería la elección sobre la satisfacción sexual, que pone una marca en la vida de Joe; una mujer que a sus cincuenta años, hace un relato autobiográfico a Seligman, un hombre quien la ha acogido en su casa, luego de haber sido golpeada y dejada tirada en la calle en una noche húmeda y fría. Ella comienza describiendo cómo fue el primer encuentro con su cuerpo, “a los dos años descubrí mi vagina y mis senos”, si bien ella menciona que el descubrimiento es con su vagina, en rigor, el encuentro que una niña tiene a esa edad es con una satisfacción sexual a través de su clítoris. Este suceso revela un encuentro con la sexualidad, que para el psicoanálisis son experiencias vividas en la infancia de manera corriente. Freud (1976 [1905]) en "Tres ensayos de teoría sexual" aclara que el conocimiento de la sexualidad en la niñez hace parte de la vida de todos los sujetos, por lo que este recono- 
cimiento de sus órganos genitales, corresponde a las manifestaciones sexuales en la infancia, que revelan los rasgos esenciales de la pulsión sexual (p.157).

Para Freud, estos recuerdos tienden a desvanecerse de la memoria, para dar paso a que la pulsión sexual tenga lugar en otras experiencias del orden de la sublimación, que es la desviación de las fuerzas pulsionales sexuales hacia metas nuevas para la adquisición de logros culturales (1976 [1905], p.161). Esta desviación de las pulsiones sexuales se presentan en el periodo de la latencia, donde prevalece la amnesia infantil, en la cual el autor advierte que es un fenómeno psíquico que en la mayoría de los seres humanos cubre los primeros años de su infancia, dejando claro que no en todos sucede, como en el caso de Joe, que estando adulta recuerda el episodio del descubrimiento del placer obtenido a través de su cuerpo cuando tenía dos años; este recuerdo hace posible deducir que el encuentro fue con una satisfacción sexual de carácter autoerótico, que es una de las características de la satisfacción sexual en la infancia.

Freud continúa diciendo que en la vida adulta, esos recuerdos son remotos e incomprensibles, sin embargo, esas experiencias sexuales autoeróticas vividas en la infancia, dejan huellas en la vida anímica y pasan a ser determinantes en el modo de satisfacción sexual posterior (1976 [1905], pp.158-159). Lo enunciado por este autor se hace evidente en la vida de Joe, en tanto la satisfacción sexual autoerótica obtenida en el primer encuentro con su cuerpo, es un patrón que se repite a lo largo de su vida, a manera de un goce solitario, que Lacan en su "Seminario 20, Aún" (1973) lo nombra como "goce del idiota” para hacer referencia al goce fálico en el hombre - la masturbación (p.33).

Joe continúa su relato, comentando una experiencia que prosiguió luego del descubrimiento de la satisfacción a través de sus órganos genitales, en la que ella está en el baño jugando con su amiga y busca que su clítoris tenga contacto con el piso cubierto por el agua de la bañe- 
ra, la cual le provee nuevamente un placer autoerótico. En esta escena Joe es una niña aproximadamente de siete años, que correspondería al periodo de la latencia, donde aparece lo que Freud (1976 [1905]), llama las inhibiciones sexuales al edificarse los poderes anímicos, "el asco, el sentimiento de vergüenza, los reclamos ideales en lo estético y en lo moral" (p.16o), que actúan como barreras de contención del empuje pulsional. Si bien estos diques son construidos como lo dice este autor, de manera psíquica, se requiere fortalecer su edificación con la intervención de un Otro social, que como representante de la autoridad le ponga límites a los excesos sexuales, de no hacerlo, el sujeto puede quedar fijado a una sexualidad infantil, o como Freud lo nombra, a un goce perverso polimorfo, que es en esencia, la fijación a varias formas de satisfacción sin que medie la ley, y que deja al sujeto con una disposición a la repetición de esa forma de satisfacción. Freud afirma que, aunque los diques anímicos no son producto de la educación o de la imposición de una autoridad externa, éstas contribuyen en su permanecía (p.161).

Este cuadro cinematográfico que expone esta vivencia de Joe, revela que hay un encuentro con un exceso de satisfacción en el periodo de la latencia, que al no ser limitado por el Otro, contribuye a que quede fijada a un goce de carácter autoerótico, y con una disposición a la repetición a partir del encuentro en algún momento de la vida con una contingencia que lleve a Joe a la repetición de esa manera de gozar, sin tener consciente el sentido de por qué lo hace.

La satisfacción sexual autoerótica de Joe estuvo presente en su vida desde que descubrió el placer a través de su clítoris y sus senos, siempre buscando momentos de autosatisfacción. Al respecto Freud (1976 [1905]) dice:

De tiempo en tiempo irrumpe un bloque de exteriorización sexual que se ha sustraído a la sublimación, o cierta práctica sexual se conserva durante todo el periodo de latencia hasta el estallido reforzado de la pulsión sexual en la puber$\operatorname{tad}$ (p. 162). 
Ese estallido de la pulsión sexual en la pubertad, se manifiesta en los actos autoeróticos y en el interés por descubrir más acerca de la sexualidad, que Joe refuerza cuando encuentra en un libro de medicina de su padre, los órganos sexuales de la mujer, siendo de su especial interés el clítoris.

La búsqueda de la satisfacción sexual a temprana edad, conlleva a Joe a seguir experimentando con otro tipo de elementos, con los que pueda tener contacto con su clítoris. Relata este acontecimiento en la época escolar de la siguiente manera, "cuando quería orinar me subía a las cuerdas y me quedaba ahí por horas con la soga entre las piernas, la llamábamos la sensación”. Freud revela que la zona rectora de satisfacción en la niña es el clítoris, esto indicaría que Joe en su infancia y en su pubertad obtiene satisfacción mediante la estimulación de su clítoris, aunque Freud va a decir que con la pubertad llega la oleada de represión para la mujer y el refuerzo de las inhibiciones sexuales, lo que conlleva a que haya una afectación de la excitabilidad del mismo (1976 [1905], p.201). Cuestión que tampoco se evidencia en Joe, puesto que en ella no hay muestra de inhibición sexual en la pubertad, sino una búsqueda de satisfacción que como se ha venido diciendo es de carácter autoerótico, o lo que Lacan llama goce solitario, que de no renunciar a él, el sujeto tendría dificultad para el vínculo social.

De acuerdo a lo anterior, si bien Joe está instalada en un goce solitario, en su infancia, posteriormente en su adolescencia y luego en la adultez, sus encuentros sexuales con los hombres son sin el Otro, esto es porque ella solamente busca su satisfacción. Este patrón de auto satisfacción que es repetitivo en la sexualidad de Joe, se puede pensar a partir de que sus vivencias sexuales en la infancia y en la latencia, no contaron con el límite del Otro paterno y materno para permitirle articular sexualidad y ley, lo que ocasiona en el sujeto es una fijación a un goce solitario, goce sin el Otro de la ley. 


\section{En la infancia: encuentros y desencuentro en el vínculo con el Otro ma- terno y paterno}

\section{La relación con el Otro materno}

El encuentro con su satisfacción sexual en la infancia se enlaza con las vivencias en la relación con sus padres, que parece estar dividida entre el amor del padre y la indiferencia de la madre, pero con el elemento en común de la no regulación de esta satisfacción. Por un lado, hay una madre que está entregada a su propio goce, que según lo muestra la película y lo relata Joe, es una satisfacción que está enfocada en un goce solitario, elemento que el director ilustra al situar como preferencia de la ésta, jugar al solitario, en el que no es necesario que haya otro para jugar la partida de naipes, es a través de este que la madre obtiene una satisfacción sin la presencia de un otro. Escena que es contigua al momento en el que ésta intenta poner límite a su hija cuando está jugando plácidamente con su amiga, obteniendo una satisfacción autoerótica al deslizarse por el piso húmedo del baño; es cuando el padre interviene sugiriéndole "déjala sola”, a lo que Kate, la madre de Joe no se opone, para disponerse a seguir en su goce solitario a través del juego con las cartas.

Kate representa lo que es una madre contemporánea, a la cual su hija cuestiona en este caso por estar siempre en función de su goce, su goce solitario. Así lo señala Sofía Fernández (2013), en su texto "La familia y la nuevas formas de satisfacción sexual de los adolescentes", cuando dice que los padres de la contemporaneidad no logran cumplir su función; siendo la materna, además de proteger, ser pasadora de deseo, es decir, debe dejar que el padre opere como referente de ley, y la función del padre es articular el deseo a la ley, pero esto no sucede porque en la época actual porque tanto la madre como el padre están más pendientes de su propia satisfacción pulsional, dejando de lado el proceso de formación de sus hijos y la inclusión de estos en lo social y cultural (p.195). 
Llama la atención que Joe critique el goce solitario de su madre y es a esta satisfacción del Uno sin el Otro al que ella se identifica de manera inconsciente. Freud (1900 [1899]) en el texto "La interpretación de los sueños", afirma: "la identificación no es la simple imitación, sino apropiación sobre la base de la misma reivindicación etiológica; expresa un -igual que- y se refiere a algo común que permanece en el inconsciente" (p.168). Por lo tanto, ese común que permaneció en el inconsciente de Joe y que, como efecto, produce una repetición de lo sintomático de su madre, fue la identificación a un goce solitario que hace que extraiga al otro de su vida amorosa, hallando así el medio para obtener su satisfacción.

Joe se apropia por medio de la identificación hacia su madre, de varios rasgos que el director de la película deja entrever, no solamente de una satisfacción en la que el otro no está presente, sino, en aspectos como la insatisfacción histérica y la relación que posteriormente ésta tiene con su hijo. En la primera, Joe se refiere a su madre como una perra fría, "supongo que era lo que se dice una perra fría", frase que induce a pensar en la insatisfacción sexual de su madre, que pudo haber promovido a la elección de un goce solitario a través de un juego de cartas. Joe se muestra como una mujer insatisfecha, al no conseguir ser colmada por el otro, cuando le demanda "llena todos mis huecos por favor", frase que ésta pronuncia al inicio de la cinta, que queda inicialmente como enigmática, pero posteriormente en lo que ella relata va tomando fuerza al relacionarse con su deseo siempre insatisfecho, ningún hombre le va a llenar todos sus agujeros, por lo que siempre quedará un resto de insatisfacción. La forma como se enfrenta a esta es la ninfomanía, como la búsqueda incesante de placer, pero siempre insatisfecha.

El otro punto de identificación, se refiere a la relación con su hijo, "el amor eterno no era el problema. Era solo que cada vez que lo miraba a los ojos, tenía ese sentimiento de que había sido descubierta, es algo difícil de decir de un niño, que mi amor no estaba siendo retornado. Pero solo era mi percepción”. El amor no estaba siendo retornado, 
como si repitiera con su hijo el no retorno del amor por parte de su madre, que solamente aparece en dos escenas de la película, la primera cuando intenta regular el juego de su hija con la amiga en el baño, y no lo hace por la intervención del padre; y la segunda cuando muere el padre de Joe. En estos dos cuadros, se ve una mujer indiferente y hostil con respecto a su hija y a su esposo, por lo que puede decirse que no es casualidad, que Joe ante el acontecimiento de tener un hijo, no haya abandonado su goce, y lo haya puesto por encima de su familia y de su ser como madre. Ella no renuncia a su goce, y lo confirma más adelante cuando pronuncia esta frase, "vivir por el placer siempre. No creo que tenga elección”. Es decir, vivir para el goce siempre sin que el Otro ponga límite, esa fue su elección.

\section{La relación con el Otro paterno}

El padre se muestra como una persona amorosa con la que ella puede compartir otros aspectos de su vida y de la cual se siente gratificada, pues dice haberlo amado mucho. Sin embargo, por parte de éste hay una labilidad en la trasmisión de la ley que no le permite regular la satisfacción sexual de Joe, llevando a que su hija encuentre cómo vérselas con su goce y realice la construcción fantasmática "soy un ser para vivir por el placer siempre”. Para el psicoanalista Luis Fernando Gómez (2007), quien trabaja sobre las mutaciones del nombre del padre y sus mutaciones en la familia y sociedad actual, señala que hoy los padres están más presentes en la vida de sus hijos con respecto al amor y a los cuidados, pero afirma, "entre más está el padre del amor, más cae el de la autoridad” (p.33), situación que se ve claramente en la relación padre-hija que el director expone en su filme. Este psicoanalista propone que la función paterna hoy está desdibujada en la sociedad, pues ya no hay uno que oriente y se apropie del poder, "todos somos orientadores”, incluyendo el mercado global y sus objetos, por lo que señala que los sujetos establecen su propia ley respecto a su propio goce (p.33).

Esta proposición no está lejos de ilustrar las decisiones que toma Joe con respecto a su actividad sexual, pues ella misma dice que es una 
ninfómana y se ama por serlo. Ante la ausencia del Otro de la ley ella tomó el control de su satisfacción desde que estaba pequeña, "no era que extrañaba a mi mamá, no creo que extrañé a mi papá aun cuando fue muy bueno conmigo. Ahí estaba completamente sola en el universo, fue como si todo mi cuerpo se llenara de soledad y lágrimas”, esto refleja junto con la posición que cada uno de los padres adopta, que es ella quien decide qué hacer con su satisfacción sexual, en tanto la articulación entre sexualidad y ley no se dio por la falta de prohibición por parte de sus padres a los excesos de sus vivencias sexuales, lo que contribuyó a su elección de gozar sin el otro, y cuando éste está presente, solamente es un medio para su propia satisfacción.

Los padres de Joe no distan de lo que reflejan los padres de hoy, como dice José Fernando Velásquez (2007), cuando habla de los aspectos que caracterizan a la familia de la época de la hipermodernidad, en donde predomina la lógica individual "en la que cada cual cultiva su pequeño goce personal” (p.19). Este psicoanalista menciona ciertos aspectos que describen a las familias de hoy y por lo tanto promueven a su desanudamiento, como lo es la idealización individualista de la pareja, el no cumplimiento de la función materna y paterna para con el hijo y los hechos que tocan la paternidad. Con respecto a las madres de hoy, dice que cada vez son más diversas y plurales, pues la mujer actual reivindica su derecho al deseo y al goce, aún sin el consentimiento de su pareja, mientras que con respecto a los hombres, "se ha producido una desfalicización de su estereotipo, de su imagen de energía y fuerza, torpeza emocional, autoridad" (p.22), talantes que promueven a que la función paterna en muchas situaciones, se límite solamente al cubrimiento de las necesidades básicas o a brindar amor.

Se espera que la articulación entre la función de la madre de trasmitir a su hijo que no es producto de un deseo anónimo y darle lugar a la transmisión de la ley, y la función del padre de articular deseo y ley, dé como resultado, que el sujeto construya su propio deseo y haya regulación con respecto al goce, esto permite el ingreso del sujeto a la cultura y el vínculo con los otros. De no darse estas condiciones, se producen 
otros efectos que se pueden traducir en excesos que pueden llevarlo a realizar prácticas donde el resultado es el daño a sí mismo, como sucede en algunas manifestaciones contemporáneas de la sexualidad (Fernández, 2013, p.191).

Este planteamiento permite relacionar las vivencias de Joe en su infancia con respecto a sus padres, y lo que caracteriza a la familia hoy, en la cual los padres no están a la altura de su función, para permitirle a su hijo regular su tendencia a la satisfacción. Joe es una mujer que busca satisfacerse por medio de sus actos sexuales donde no hay un límite por parte de otros ni de ella misma, quedando como característica en Joe un goce sexual en el exceso.

\section{Encuentro con la contingencia y la elección de goce}

\section{En la adolescencia: encuentros y desencuentros}

"Tal vez mis expectativas románticas eran algo altas", frase con la que Joe inicia el relato sobre su adolescencia, la cual devela el desencuentro amoroso propio de esta edad. Así lo refiere Sofía Fernández (2014) en su texto "Despertar de la primavera y el goce femenino", al afirmar que cuando el púber tiene su primer encuentro con el Otro sexo obtiene una nueva satisfacción para el cual no hay respuesta (p.2). Esto se evidencia en Joe al decir que tal vez sus expectativas románticas eran algo altas, y relata la escena donde tiene su primera relación sexual; en ella habita el deseo de encontrar en un hombre algo que la satisfaga, pero con lo que se tropieza es con el desencuentro, como señala el psicoanalista Mario Elkin Ramírez (2014), en su libro “Despertar de la adolescencia”, del lado femenino se sitúa el anhelo de ser causa del deseo de un hombre sobre la vertiente del amor (p.235). Pero con lo que se encuentra Joe es con un hombre que ante la invitación de ser el elegido para tener su primer encuentro sexual, actúa en consecuencia y la ubica como un objeto de satisfacción sexual, encuentro que no está mediado por el amor. Sin embrago, al ella ofrecerse a Jerome, esperando tal vez encontrar el amor o el placer sexual, se tropieza es con la 
desilusión, porque como afirma este psicoanalista, la mujer aspira ser amada por un hombre, mientras que éste únicamente quiere un goce sexual (p.236).

¿A qué se despertó Joe a partir de su primer encuentro sexual con Jerome? Desde el psicoanálisis se podría decir que a una nueva forma de goce enigmática, que no alcanza a ser recubierta por los significantes que tiene para dar respuesta frente a esta nueva forma de satisfacción. Esto es lo que Lacan llamó en su "Seminario 20: Aún" (1973) "no hay relación sexual”, pues en la relación con el otro siempre hay una falla (p.4). Esta enunciación de Lacan, la referencia Mario Elkin (2014) en su texto, haciendo énfasis en que no hay armonía ni complementariedad entre los sexos, explicando que "la falla estructural de los sexos da una disimetría irreductible que sostiene que no hay relación sexual" (p.222-223), lo cual llevado a la experiencia de Joe en su primer encuentro sexual, evidencia, en tanto, lo que ella buscaba ubicándose del lado femenino, era ser amada por un hombre, que no corresponde con la respuesta de Jerome, que desde una posición masculina la ubica como un objeto para su satisfacción sexual sin que medie el amor.

Cuando Joe sale desengañada de la casa de Jerome, por no haber encontrado lo que había ido a buscar, anuncia no volver a tener relaciones sexuales, pero cuando su amiga la invita a conseguir hombres con quien tener sexo en el tren, ella elige hacerlo, para obtener como premio una bolsa de dulces. Entonces utiliza la táctica sugerida por su amiga, "lo hice todo bien, mirarlo a los ojos y sonreír" y así logra la victoria en la competencia de quien más hombres seduce para tener sexo. Pero lo que realmente surge en ese exceso en el sexo es una ganancia de goce, que se incrementa luego de la competencia sexual. Esta invitación se constituye en la vida de Joe en una contingencia, que se entiende como lo que puede suceder o no en la vida un sujeto, y que puede precipitar una elección, que para su caso, es devorar a los hombres teniendo sexo sin la inclusión del otro como objeto amoroso, y en este acto de devoración obtiene una satisfacción, que en el filme es representado cuando devora la bolsa de dulces que ha ganado en esa competencia. 
A partir de la construcción fantasmática que hizo en su infancia de "vivir por el placer siempre"; viene la contingencia que es la invitación de la amiga de tener sexo en exceso en el tren, la cual ella no rechaza, lo que permite la articulación entre la contingencia y su construcción fantasmática. Esto la lleva a una elección, la ninfomanía que, desde su singularidad, fue la búsqueda de su propia satisfacción en el exceso sexual con otros pero sin ellos como objetos de amor. Y en cada acto sexual hace la demanda siempre insatisfecha de "llena todos mis huecos". $\mathrm{Al}$ respecto el psicoanalista Ignacio Cruz (2014), al hacer un análisis de este filme dice "ella insiste en que algo de lo fálico puede colmarla, pero su condición femenina le hace evidente que siempre queda un resto insatisfecho" (párr.7).

\section{En la vida adulta: de la demanda histérica a la insatisfacción}

"Yo descubrí mi poder como mujer, y lo usé sin ningún consentimiento, eso es completamente inaceptable". Los actos de Joe estuvieron ligados a la satisfacción de siempre obtener lo que ella quería, aunque esto le generara dificultades con los otros. "No puedo ser yo sin destruir algunas cosas”, más que la necesidad de hacer daño, está la necesidad de no sufrir, por esto busca relaciones en las que no haya ningún vínculo amoroso, aunque ésta condición no se daba del lado opuesto, pues los hombres que eran únicamente para tener sexo, sí buscaban en ella algo más, por lo tanto Joe pierde el control de estas relaciones, ya que estos hombres le demandan algo más que sexo, le demandan amor, situación a la que ella no puede enfrentarse, porque para ella estaban en la misma serie, eran para tener sexo sin amor, con la ilusión fantasmática de que alguien llenara todos sus agujeros.

Esta búsqueda incontrolada de sexo, deja ver a una mujer insatisfecha, característica que se ubica en una estructura de neurosis histérica. Juan David Nasio (1990) dice que el sujeto histérico construye su relación con el otro sobre la base de su fantasma inconsciente, "un fantasma en el que encarna el papel de víctima desdichada y constantemente insatisfecha" (p.8). A partir de esta descripción que Nasio hace 
en su libro "El dolor en la histeria”, y del análisis de la narrativa de Joe, es posible señalar que a lo largo de su vida, estuvo centrada en hacer efectivo su fantasma, "vivir por el placer siempre".

Nasio argumenta que el sujeto histérico prefiere mantenerse en la insatisfacción, porque ante todo es un ser de miedo, y el miedo es justamente quedar satisfecho, vivir un goce máximo, por eso Joe no se enamora para poder tener sexo satisfactorio, porque cuando se enamora pierde toda la excitación sexual, y unir estos dos aspectos es vivir lo que pareciera ser la completud, aunque ya se ha dejado claro que no existe la complementariedad entre los sexos, ante la posibilidad de Joe de vivir las dos experiencias en su máxima expresión se ve en la obligación de renunciar a uno, sea al sexo o al amor.

En 1888 en "Histeria" cuando Freud hizo la descripción de los síntomas histéricos, enfatizó en que éstos están ligados al cuerpo, entre los que se encuentran las perturbaciones de la sensibilidad, que consiste en la anestesia de alguno de los órganos del cuerpo como la piel, las extremidades, los músculos, los nervios, entre otros, y puede abarcar la lengua, la laringe o los genitales en su totalidad, sin embargo, esta anestesia de los órganos no perturba el movimiento motriz de los mismos (Freud,1976[1888], p.49). La escena que el director presenta, que confirma lo dicho por Freud con respecto a la perturbación de la sensibilidad en Joe, es cuando vuelve a encontrarse con Jerome años después de su primer experiencia sexual, entonces comienza una relación afectiva donde desde el inicio está involucrado el sexo y el amor, pero después dice, "no puedo sentir nada", en medio de una relación sexual donde el amor pareciera ser el protagonista, Joe pierde la sensación sexual en su vagina, "lo peor que me ha pasado es que en ese punto, en segundos perdí toda la sensación sexual, mi vagina simplemente se entumeció". O si se observa de manera contraria, cuando no hay sentimientos, es cuando adviene toda la excitación en Joe, esto se refleja en la escena donde muere su padre, "cuando él murió no me quedaba ningún sentimiento. No sé qué me pasó, fue bastante vergonzoso, lubriqué”. Esta es pues la muestra de que ella no puede hacer una inte- 
rrelación entre el amor y el sexo, por lo que ha tenido experiencias donde se enamora y no puede tener una satisfacción sexual y otras donde tiene sexo sin el otro, es decir, sexo sin amor, y es allí donde sí obtiene una satisfacción. Eh aquí otra analogía entre los encuentros y desencuentros que se presentaron en su vida, sexo sin amor - amor sin sexo.

A pesar de esta situación, comienza una relación familiar con Jerome, de la cual nace un hijo, "en ese periodo donde toda sensación sexual era negada, era seguro y domésticamente confortable”, pero con el tiempo la sensibilidad fue volviendo a su vagina, reivindicando su actividad sexual con Jerome y con otros hombres, pues su pareja no lograba satisfacer la demanda de Joe de que el otro en el encuentro sexual llene todos sus agujeros, por lo que Jerome promueve a que ella tenga encuentros sexuales con más hombres, argumentado que ella es un tigre que él no puede alimentar; oportunidad que Joe no rechaza y día tras día emprende la búsqueda de hombres, generando situaciones donde pudiera hacer su cacería, así lo describe ella:

Por primera vez tuve el placer de tener a ocho hombres revisando el auto, una estupenda combinación de ocho hombres para follar. Algo como 44mil si no me falla la matemática, y uno de ellos hará encender el auto y me dará todo el tiempo que necesito.

Esta expresión devela su deseo insatisfecho de ser colmada en el encuentro con un hombre. Realidad que Jerome no soporta y se va de casa, nuevamente Joe queda sin el amor, pero la búsqueda de sexo no cesa.

La búsqueda de satisfacción que Joe hace se contrapone a la elección de amor, pues se enamora de un hombre que no la satisface en su demanda de ser colmada en su goce, así ella logra perpetuar su fantasma histérico de insatisfacción. Deseo insatisfecho que se evidencia desde su infancia, porque, aunque amaba a su padre, quien era un ser para el amor, ella manifiesta sentirse sola en el mundo. Su madre tampoco logró colmar sus expectativas, para ella era una perra fría que prefería jugar al solitario. Mientras tanto Joe encontró la manera de propiciarse 
su propio goce a través del sexo, donde la demanda que hace en relación a su sexualidad es que le llenen todos sus agujeros, lo que se convierte en una demanda sintomática debido a su imposibilidad.

\section{Del desencuentro amoroso al encuentro con el goce femenino}

\section{Amor y traición}

Ninfomaníaca. Olvídate del amor, es el título con el que el director ha nombrado la cinta que se estrenó en diciembre del año 2013. Se podría pensar en ponerle signos de interrogación al predicado olvídate del amor, dejando como una nueva opción “¿olvídate del amor?”, aunque el título en su forma original pareciera ser un ideal de la época; ya que hoy prevalece es el comportamiento hedónico y sujetos sin mayor preocupación por implicarse con el otro, quien podría hacer llamados y demandas propias de lo que es consentido en el campo del amor. Además, porque como dice la autora Liliana Lamovsky (2004), el amor limita la degradación erótica que se incrementa cuando solamente se busca la satisfacción (p.5), como lo demuestra Joe en sus múltiples encuentros sexuales que tienen como meta única el goce sexual. No obstante, aunque el título del filme, sugiere al espectador que la palabra amor pareciese no estar vinculada con su contenido, en el transcurrir de las escenas se descubre que el director no la utiliza de manera casual, sino que tiene un lugar casi tan protagónico como la palabra ninfomaníaca.

El amor en Joe tiene la característica de estar anudado con la desilusión. A lo largo del filme, puede verse cómo el director ilustra que en los distintos vínculos amorosos que tuvo desde su infancia, hay una respuesta de engaño por parte del otro. Esto se observa incluso cuando siendo una niña, aún podría esperar el amor de su madre, pero ésta prefiere entregarse a su goce solitario. Más adelante en su adolescencia y en su adultez, se ve implicada en una serie de relaciones de amistad y amorosas, de las que sale nuevamente decepcionada, por lo que ella opta por hacerle la contienda al amor sin obtener los resultados esperados, pues hasta los últimos minutos de la película, se ve como ella ter- 
mina creyendo en esa palabra que el director expone como si no hiciera parte de la vida de esta mujer, pero que repetidamente se manifiesta y pareciera hacer estragos en ella.

$\mathrm{El}$ amor comienza a revelarse en la vida de Joe y al mismo tiempo ella comienza a rebelarse en su contra. Con su amiga hacen parte de lo que sería un club donde se le hace tributo a la vagina, "follar y tener derecho a estar caliente, pero era por rebelión”, rebelión al amor, entre menos amor había en la vida de Joe, más era la excitación sexual. Es así como esta mujer logra construir lo que sería una posición subjetiva en relación a la sexualidad, para poder tener encuentros sexuales en exceso, ubicando el goce solitario como ingrediente principal y rechazando al amor, porque como lo dice Lamovsky (2004), hoy predomina un mundo sin amor, estamos en la búsqueda de la satisfacción inmediata que empuja a la obtención del máximo goce posible y destruye todo posible objeto de amor (p.4). Joe no hacía vínculo con los hombres con los que podía obtener su satisfacción, sino que el vínculo era con el club y con su amiga, quien abandona la hermandad cuando se enamora, renuncia al vínculo pronunciándole esta frase, "piensas que sabes todo sobre el sexo, el ingrediente secreto en el sexo es el amor", palabras que Joe no logra articular a su dinámica subjetiva, pues para ella el goce sin el otro es a lo que hay que decirle sí y al amor no.

Esta escena revela una vez más, que Joe queda sola, y con la convicción de que el amor no tiene sentido, ella lo dice así, "para mí el amor, era lo último que allá pudo añadir, todo lo demás no tenía sentido. De cien crímenes cometidos en nombre del amor, solo uno es cometido en nombre del sexo", lo que refuerza sus encuentros sexuales con distintos hombres, y sin la compañía de su amiga comienza la búsqueda de sexo sin el otro, que se convierte en un estilo de vida, que desde el psicoanálisis lo podemos nombrar como estilo de goce, como lo dice Colette Soler (2004), en su libro "Lo que decía Lacan de las mujeres", las mujeres de hoy se consagran al goce, ya no se limitan para ir a la cama con un hombre, "a veces incluso coleccionan amantes", y ante la pregunta de ċqué quiere una mujer?, la respuesta es: quiere gozar 
(p.62). Y esta mujer de hoy no está lejos de ser encarnada por Joe, que goza de la carne, pero a pesar del exceso queda insatisfecha, porque quiere y puede gozar de los hombres, pero no logra que estos colmen su demanda de que le llenen todos sus agujeros.

Pero la demanda de Joe está lejos de ser atendida y satisfecha aunque tenga a muchos hombres con quien llenar sus agujeros, porque lo que ella busca es la completud, que no se trata del cuerpo sino del ser, y es por la vía del goce del cuerpo que ella espera ser colmada, pero Lacan (1973), anuncia que "el goce, en tanto sexual, es fálico, es decir, no se relaciona con el Otro en cuanto tal” (p.4), lo que demuestra que en el goce sexual sigue siendo un goce de órgano, y Lacan deja muy claro que para que el hombre pueda hacer el amor con una mujer, éste también tiene que aceptar la castración para poder dejar de lado la función fálica (p.29). Y Joe no encuentra a este hombre, ni en su primera relación sexual con Jerome donde la ubica como objeto de goce, ni después cuando éste le dice que ella es un tigre que él no puede alimentar, porque Jerome cree que la forma de colmarla es a través de la función fálica, ambos lo creen, y por eso Joe acepta continuar teniendo encuentros sexuales con otros hombres, propuesta que le hace Jerome.

En la entrevista realizada a Jacques-Alain Miller (2011[2008]) por la "Psychologies Magazine" señala que la expresión de Lacan "Amar es dar lo que no se tiene" hace alusión a que amar es reconocer la falta y darla al otro, y para poder dar la falta al otro hay que asumir su propia castración, por eso el amor se ubica desde una posición femenina (párr.1). Podría pensarse que Joe no asumió su falta, ya que quería sentirse completa, y por ello comienza a tener relaciones sexuales con diferentes hombres, encuentros sexuales que están en la vía de hacer existir su fantasma y su demanda histérica.

Finalmente encontrarse con el amor se convierte en lo inevitable, cuando en busca de un trabajo se reencuentra con el hombre al que ella entrega su virginidad sin reparo. El amor por Jerome la hace perder el control, y la hace sentir avergonzada y deshonesta, pues está en contra de sus principios -sexo sin amor-, así lo manifiesta: 
Este amor idiota me hacía sentir humillada, me sentía algo deshonesta. El erotismo es como decir sí, el amor te hace no pensar en las cosas, se antepone bien alto. ¿Cómo dices sí cuando quieres decir no? Algo así... Estaba avergonzada en lo que me había convertido, pero estaba más allá de mi control.

Sin embargo, no puede evitar enamorarse, porque el amor siempre estuvo más allá de su control. Joe tuvo las situaciones sexuales bajo su dominio por eso enfatiza que es más fácil decirle sí al erotismo y no al amor, pues éste le pone límites al goce. El amor es un significante del que Lacan (1973), se ocupa en el "Seminario 20, Aún”, señalando que "el amor se apunta al sujeto, al sujeto como tal, en cuanto se le supone a una frase articulada, a algo que se ordena, o puede ordenarse, con toda una vida". Dicho esto, continúa exponiendo que "un sujeto como tal no tiene mucho que ver con el goce, pero en cambio su signo puede provocar el deseo. Es el principio del amor" (p.21). Lo que significa que en tanto deseo se contrapone al goce, entonces el amor que es un signo del deseo, puede hacer condescender el goce en el sujeto.

"Lacan intenta poner en función al amor como aquello que se introduce para establecer la conexión con el Otro" (Miller, 2011 [2008], p.157), el amor es lo que le permite a Joe hacer vínculo, y lo logra en la medida que este tiene lugar en su vida. Por eso el encuentro con Jerome hace que suspenda su actividad sexual con otros hombres por largo tiempo, porque lo que ocurrió fue el encuentro con el amor, donde pudo establecer el vínculo que no logró en sus múltiples encuentros sexuales con otros hombres. Pero así como no logra evitar enamorarse de él, tampoco puede evitar la decepción que le deja que este se case con otra mujer, lo que ella lee como una traición, produciendo en ella un desengaño, al darse cuenta de la verdad, de que ella no es el objeto amoroso de él.

Cuando Jerome deja a Joe, ella decide aumentar sus encuentros sexuales, "reaccioné agresivamente intensificando la caza por los hombres", porque lo que ocurre, es que por primera vez se decide a comunicarle sus sentimientos, y esto produce en ella un reconocimiento como sujeto, Lacan lo dice así "de alguna manera a los sujetos, evocar sus 
sentimientos sería tal vez reconocerlos demasiado en cuanto a sujetos" (p.27). Pero ese reconocimiento que Joe alcanza a tener, se desvanece al encontrar como respuesta que Jerome no está para acogerla en el amor, lo que hace que vuelva a prácticas sexuales que evidencian un exceso de satisfacción. Esta es la época en la que más tiene sexo con diferentes hombres en donde solamente obtiene placer de órgano; nuevamente se tropieza con el sin límite que le deja la ausencia del amor.

Después de una temporada en la que Joe pareciera haber encontrado su lugar en el exceso sexual, Jerome se resiste a salir de su vida, y en lo que pudiese ser una total coincidencia se encuentra nuevamente con él, y aquí vuelve el amor a ocupar un lugar en su existencia, pero es en el encuentro con el amor que pierde toda la excitación sexual, es cuando hay un entumecimiento de sus órganos genitales, Joe no vuelve a sentir placer. La psicoanalista Mónica Torres (2012) en "Cada uno encuentra su solución," hace énfasis en que entre el amor, el deseo y el goce no hay coincidencia (p.11), situación que se ve reflejada en la relación que Joe tiene con Jerome, donde habita el amor pero por parte de ella se pierde toda la excitación sexual, pues como señala Torres, "el deseo que siempre pertenece al registro simbólico, significante, va por un lado y el goce, que se representa a nivel del cuerpo y pertenece al registro de lo real, va por el otro" (p.19).

Entre Jerome y Joe no existe la relación sexual, hay la disimetría del encuentro entre los sexos, pero Lacan (1973), nos deja saber en el "Seminario 20, Aún" que "el amor suple la ausencia de la relación sexual” (p.17), frase que utiliza Jacques-Alain Miller (1998), en su libro "El partenaire-síntoma", para explicar que una de las funciones del amor es suplir la relación sexual que no existe, y al mismo tiempo le da al hombre y a la mujer un estatuto, que en el hombre continúa siendo pulsional, mientras que en la mujer propicia otro tipo de goce, el goce femenino, que va más allá del falo, pues en la mujer hay una revalorización del amor, ya que su goce está ligado al amor del Otro (p.159). Pero Joe le cuesta hacer esta revalorización del amor, ella elige revalorizar el goce, en la ausencia del amor, es precisamente donde halla el máximo goce. 
Ya estando adulta y luego de la separación con Jerome y de que éste se llevara a su hijo, conoce a una adolescente a la que llama "P"; su objetivo es incluirla en su nuevo trabajo donde cobra dinero a unos hombres, haciendo uso de los puntos débiles con respecto a su sexualidad que ella muy bien sabe identificar. Pero la historia cambia cuando su relación con $\mathrm{P}$ trasciende los escenarios profesionales para convertirse en una relación afectiva, que el filme revela en un principio como una relación de madre e hija, pero después pareciera convertirse en una relación de amor. Aquí Joe no puede tener relaciones sexuales debido al desgaste de su cuerpo, "en todo este tiempo mi actividad sexual se había detenido. Mi vejez había afectado mis sentidos”, el amor se encarga de poner los límites correspondientes al goce en Joe; se puede ver en ella una mujer ilusionada con su nuevo amor, que orienta y protege sin precaución, sin sospechar que lo que ella le ha enseñado en el negocio, P lo utiliza para traicionarla, cuando en una de las noches de trabajo, hay que cobrarle dinero a un cliente, que luego Joe descubre que es Jerome. Ésta desiste cobrarle el dinero, ya que sus métodos incluyen violencia y humillación al deudor, por lo que opta por enviar a $\mathrm{P}$ a cumplir la misión en seis noches, pero en la última noche $\mathrm{P}$ no regresa a casa, y Joe descubre que su nuevo amor ahora tiene una relación con este hombre. Nuevamente Joe es protagonista de la traición que le propicia el amor.

\section{Desencadenamiento del goce femenino}

"Fui engañada, fui un mal ser humano", expresión con la que Joe comienza el relato de su historia de vida que estuvo conducida por su adicción al sexo, o, como ella insiste en llamarlo, por su ninfomanía. En el transcurrir de la película se observa como Joe tiene encuentros y desencuentros con el amor, donde cada uno de ellos deja como resto una mujer traicionada que responde con el exceso en la sexualidad. La traición y el desengaño desencadenan en ella lo que desde el psicoanálisis se ha llamado el goce femenino - el exceso - , el exceso en la sexualidad, la búsqueda de goce por devorar hombres para que llenen todos sus agujeros. Y esto se manifiesta en las escenas en las que ella 
intensifica sus relaciones sexuales sin conseguir la satisfacción, al punto de visitar un centro de masoquismo para ser golpeada, ya que el sexo cotidiano se vuelve insuficiente para ella.

José Fernando Velásquez (2014), define el goce femenino haciendo alusión a lo más singular del goce que Lacan expresa en su última enseñanza. Velásquez define este goce como el que se realiza sin el falo, sin el Otro del significante, que no dice sino que se muestra, que está "fuera de las palabras, de la lógica, del deseo y del sentido común; y tiene cierta apetencia por el cuerpo donde aparece como fenómeno fijo" (p.198). El cuerpo es la vía por la cual Joe hace existir su goce, desde su infancia, cuando el encuentro con su cuerpo le produce una satisfacción sexual, en la juventud con sus múltiples encuentros sexuales y en su vida adulta cuando el placer autoerótico ya no le es suficiente y lo busca a través del dolor.

"Soy una mujer que se atiende aquí", afirmación que le hace Joe al hombre sádico que atiende en el centro y el cual no quiere recibirla, pero ella insiste logrando ser una de la lista de mujeres que cada noche asiste a este lugar. "El último intento que hice para rehabilitar mi sexualidad". Tres años después del nacimiento de su hijo, en busca de rehabilitar su placer sexual que ha perdido cuando vuelve a encontrarse con Jerome, llega a un centro de sadomasoquismo donde recibe golpes en las caderas con diferentes objetos que le propician satisfacción sexual. Collete Soler (2004), hace referencia del masoquismo exponiendo las ideas de Freud cerca de este, explicando que para Freud, el masoquismo es primordialmente femenino, y que el interés del sujeto maltratado es ser el objeto del padre, aspirar a ser pegado es como ser la mujer del padre, pero Freud hablaba primordialmente de los hombres que se ubican en posición femenina (p.70). Soler anuncia que el masoquismo es una suplencia a la no relación sexual. Nuevamente Joe busca de alguna manera ser colmada en la relación con el otro, esta vez por medio del masoquismo, por medio del goce sexual que le produce su cuerpo, pero nuevamente queda insatisfecha, porque el masoquismo según Freud es una demanda de amor (p.71). 
Para poder asistir a sus sesiones sadomasoquistas, Joe debe dejar a su hijo al cuidado de una niñera en la noche. En varias ocasiones lo dejó solo para acudir a la cita, ya que Jerome está por fuera de casa y la deja sola al cuidado del bebé. Si bien, cuando se habla de Medea, mito escrito por Eurípides (431 a. C), lo que se encuentra es una mujer que mata a sus hijos por la traición de su hombre, en Joe se ve es una mujer que abandona a su hijo en las noches para tener una experiencia sexual satisfactoria a través de una experiencia de dolor, poniendo en peligro la vida de este. Justo en una de esas noches Jerome llega de imprevisto y encuentra a su hijo abandonado en medio de la noche. Pero este acto que parece difícil de entender, es lo que la psicoanalista Marita Hamann (2014), llama lo real, para nombrar lo imposible de creer en el acto de Medea, que esta autora lo describe como el modo extremo en que se puede alcanzar el goce máximo, y lo que demuestra especialmente el suceso de Medea es que "una madre es una mujer y una mujer es no toda, no toda madre, no toda en la norma, no toda previsible" (p.185). Joe ante todo es una mujer que quiere ser satisfecha en el ámbito sexual, y esto lo que propicia es perder a su esposo y a su hijo a cambio de su goce.

Hamman dice que el goce femenino no tiene en cuenta semblantes ni ideales (p.185), cuestión que pareciera no importarle mucho a Joe con respecto a su condición de madre, pues ella no personifica el papel de la madre que cuida de su hijo y se encarga de suplirle las necesidades físicas y emocionales. Joe es una madre que es más mujer que madre, que antepone su goce y se esfuerza por satisfacerlo. Sin embargo, posteriormente Joe manifiesta sentimiento de culpa luego de que Jerome se llevara a su hijo, lo que intenta compensar enviándole dinero anónimamente. Colette Soler (2004) afirma que los cuidados del cuerpo no son suficientes para la humanización de un hijo, que debe pasar por un deseo que no sea anónimo, que sea no toda de él, pero que tampoco el amor esté perdido en otro lugar, es decir, que no sea insondable (p.125). Y en el caso de Joe, más que el amor perdido en otro lugar, ella misma está perdida en su propio goce, dejando de lado su condición de madre. 
La traición que Joe ha encontrado en el amor, va desencadenando el goce femenino, siendo su sexualidad cada vez más descomunal y autodestructiva, pero con la llegada de $\mathrm{P}$ y con ello el nuevo amor, se va viendo a una mujer que le va poniendo límites al goce, hasta que un nuevo engaño aparece, su amiga P la deja para quedarse con Jerome, traición que al ser descubierta por Joe suscita en ella el deseo de asesinarlo, expresando: "es tan difícil tomar la vida de alguien, pero diría que es más difícil no hacerlo. Para un ser humano matar es lo más natural del mundo, fuimos creados para eso". Su deseo de asesinarlo surge o porque aún lo ama y se implicó con otra mujer, o porque a la que ama es esa mujer con la que él se ha implicado. "Nada mejor que un crimen para hacer que el amor sea creíble" (Soler, 2004, p.197), lo dice esta psicoanalista cuando habla de las hazañas del amor, una demostración de amor por lo real, un crimen pasional, que aunque no es un tema de la modernidad, hoy en día pasa a ser un "suceso breve" (p.197). Pero a Joe no le funciona el arma para hacer existir el amor por medio del crimen, y en su lugar recibe la humillación de las dos personas que llegó a amar. P y Jerome tienen relaciones sexuales ante su mirada, Jerome la golpea y luego P orina sobre ella, y se van.

Este es el momento que permite el encuentro con Seligman, pues éste la halla tirada en la calle y la lleva a su casa, le ofrece su hospitalidad: comida, ropa limpia y una cama para descansar. Allí comienza a revelarse la historia de una mujer que se autodenomina ninfomaníaca, y en medio del relato y las intervenciones de su interlocutor, se va iniciando una amistad, que la misma protagonista de la historia reconoce cuando le dice estas palabras acerca de su intento de asesinato a Jerome, "gracias a mi nuevo y tal vez mi primer amigo. Gracias Seligman. Tal vez haya sido para bien. Estoy feliz de todas formas de que el disparo no haya funcionado, me hubiera convertido en una asesina”. Lo que Joe valora realmente es que la haya escuchado, y con estas palabras le da fin a su historia para disponerse a dormir, como si tuviera la intensión de descansar de todo lo que ha sido su vida y ha sido revelado en esa noche. 
Pero una traición aparece nuevamente, y esta vez usa adecuadamente su arma, mata a Seligman. Esta es la última traición que recibe Joe y que no está dispuesta a perdonar, porque éste intenta tener sexo con ella creyendo que aceptaría sin problema como tantas veces lo hizo anteriormente con otros hombres, pero a pesar de haberla escuchado durante toda la noche, no logra identificar que para ella no es posible fusionar lo afectivo con el sexo, ya que ésta de alguna manera le entrega parte de su vida, confía en él, lo considera su amigo, y lo ubica del lado del amor. Por lo que el acto de Seligman se vuelve inconcebible para ella y se desencadena el goce femenino, ya no en el exceso en el sexo, sino en un acto de asesinar al otro, y finalmente esto lleva a devolverse a la primera frase con la que comienza la película, "fui engañada, fui un mal ser humano”. Nuevamente hay un desencuentro, pues la persona en la cual confió y hace que se produzca un sentimiento, termina traicionándola, hace serie con las personas que fueron importantes para la vida de ella y a las cuales les entrega el sentimiento que ella nunca pudo comprender, el amor.

\section{A manera de reflexión final}

El análisis del filme evidencia que las experiencias que se viven en la infancia dejan huellas en el sujeto, que se revelan con fuerza cuando llega a la etapa de la adolescencia y de no rectificar esas experiencias, son una marca que se pueden convertir en un modo de repetición en la vida adulta.

La infancia de un sujeto se puede considerar como es el comienzo de lo que serían las elecciones sobre su sexualidad, bien sea regulada por la ley o no, así lo muestra el filme ninfomaníaca al develar que es precisamente en este momento de la vida de Joe en el que ella obtiene un placer autoerótico que al no ser regulado por los padres, encuentra en la repetición el medio para obtener su satisfacción sexual.

Uno de los periodos importantes en el proceso de subjetivación del sujeto y olvidado por los teóricos es el de la latencia, el cual es considerado por Freud como un tiempo para la socialización y es cuando 
se inicia el proceso de edificación de los diques psíquicos contra los exceso sexuales, estos son el asco, la vergüenza y la moral, siendo una de las tareas de este periodo contribuir en la instauración del superyó moral, construcción que si cuenta con el Otro como referente del ley, le permitirá al sujeto poner y ponerse límites con respecto a los excesos y una mayor articulación a la cultura. Es precisamente en este periodo de la latencia de Joe que el filme nos muestra como para ella lo que se da es el encuentro con un exceso de satisfacción, que al no ser limitado por sus padres, contribuye a que quede fijada a un goce infantil de carácter autoerótico que se articula a lo experimentado en su infancia, y que la deja con una disposición a la repetición de ese goce al interrumpirse la construcción de los diques psíquicos; podemos decir que en ella no se instauran cabalmente las inhibiciones sexuales propuestas por Freud.

El filme ninfomaníaca nos muestra un aspecto importante en la vida de Joe, específicamente en su adolescencia, este es el encuentro de ella con una contingencia el ser invitada por su amiga a tener sexo en exceso, lo que da paso a que continúe con la práctica sexual autoerótica, ya que sus relaciones sexuales las tiene sin que haya presencia del Otro amoroso, por lo que perpetúa su goce solitario, que como se dijo, en la infancia y en la latencia no contó con el límite del Otro paterno y materno, para permitirle articular sexualidad y ley, entonces lo que queda para el sujeto es una fijación a un goce solitario.

El desencuentro amoroso propio de la adolescencia, se plasma en la película en el momento en que Joe tiene su primera relación sexual con un hombre, allí se encuentra con la disimetría de la relación sexual. Esto es lo que Lacan llamó en su seminario 20, “Aún” (1973) no hay relación sexual, pues en la relación con el otro hay una falla estructural. Que lo podemos ver en Joe, cuando ella buscaba ser correspondida en sus expectativas de complementariedad, pero lo que encuentra es un hombre que sólo busca su satisfacción sexual y la ubica a ella como objeto de goce. Propiciando este desencuentro a que ella busque tener relaciones sexuales sin que incluya sentimientos de amor, procurándose sólo por su satisfacción sexual. 


\section{Referencias}

Casseti, F., y Di, Chio. F. (1991). Cómo analizar un filme. Barcelona: Editorial Paidós. Cruz, I. (2014). Marginación de la sexualidad. Recuperado de http://gapatencion. wix.com/gaph\#!ninfomania-marginacion-de-la-sexualidad/cptd

Fernández, S. (2013). La familia y las nuevas formas de satisfacción sexual de los adolescentes. Ponencia presentada en el seminario de la Corporación Ser Especial, Familia, crianza y salud mental. Inédito. Ciudad

Fernández, S. (2014). Despertar de la primavera y el goce femenino. Inédito.

Freud, S. (1976 [1888])). Histeria. Obras completas, volumen I (p.49). Buenos Aires: Amorrotu Editores.

Freud, S. (1900 [1899]). La interpretación de los sueños. Obras completas, volumen IV (p.168). Buenos Aires: Amorrotu Editores. 1978.

Freud, S. (1976 [1905]). Tres ensayos de la teoría sexual. Obras completas, volumen VII (pp.33-202). Buenos Aires, Argentina: Amorrotu Editores.

Gómez. L. F. (2007). La autoridad y la declinación del nombre del padre hoy. En: El niño en los inicios del siglo XXI. (p.33). Nel - Medellín. Nueva Escuela Lacaniana. Asociación Mundial de Psicoanálisis (AMP).

Hamman, M. (2014). No toda mujer es Medea. El goce femenino. Bitácora Lacaniana. (p.185). Buenos Aires: Grama Ediciones.

Lacan, J. (1972-73). Seminario 20, Aún. Buenos Aires: Editorial Paidós.

Lamovsky. L. (2004). Enlaces y desenlaces entre el amor, el deseo y el goce. Jornadas 30 aniversario efba. Revista de Psicanálise Textura, pp.5, Recuperado de http://www.revistatextura.com/leia/enlaces.pdf

Miller, J.A. (1998). El partenaire-síntoma. Buenos Aires: Editorial Paidós. 
Miller, J.A. (2011[2008]). Amamos a quien responde a nuestra pregunta: ¿Quién soy yo? Entrevista realizada a Jacques-Alain Miller por Hanna Waar para la Psychologies. Revista digital de psicoanálisis, arte y pensamiento, 278(6). Recuperado de http://www.revconsecuencias.com.ar/ediciones/oo6/template.php?file=arts/alcances/Amamos-a-aquel-que-responde-a-nuestra-pregunta-Quien-soy-yo.html

Nasio. J.D. (1990). El Dolor en la Histeria. Argentina: Editorial Paidós.

Peter, A. Jensen. (Productor), Von Trier, L. (Director). (2013). Ninfomaníaca [cinta cinematográfica]. Dinamarca: Zentropa, Heimatfilme.

Ramírez. M. E. (2014). Despertar de la adolescencia. Freud y Lacan, lectores de Wedekind. Buenos Aires: Grama Ediciones.

Santander, P. 2011. Por qué y cómo hacer análisis de discurso. Cinta de Moebio: Revista de Epistemología de Ciencias Sociales, 41(207-224), Recuperado de www.moebio.uchile.cl/41/santander.html

Soler. C. (2004). Lo que decía Lacan de las mujeres. Medellín: Editorial No Todo. Torres. M. (2012). Amor, deseo y goce. Cada uno encuentra su solución. Buenos Aires: Grama Ediciones.

Velásquez. J. F. (2007). Familia, pareja y malestar contemporáneo. En: El niño en los inicios del siglo XXI (pp. 19-22). Nel-Medellín: Nueva Escuela Lacaniana. Asociación Mundial de psicoanálisis (AMP).

Velásquez, J. F. (2014). Lo femenino hoy. Fenómeno de masas vs. automatismo de goce. El goce femenino. Bitácora Lacaniana. (pp.198-199). Buenos Aires: Grama Ediciones. 